\title{
Application of Confucious' Educational Thought in College English Teaching
}

\author{
Kaiwei Yan \\ School of Foreign Languages \\ China West Normal University \\ Nanchong, China
}

\begin{abstract}
Confucius is a great thinker, politician, educator, and founder of Confucianism. His educational thought and educational practice have positive and far-reaching impact on the education of his time and later generations, which also provide a treasure house for English teaching and learning. This paper is dedicated to exploring the connotations of Confucius' educational thought and its implications for English teaching in order to better serve the teaching practice. We mainly discuss from the following four aspects: Reform of English teaching and change of teachers' role; combination of learning and thinking and unity of knowing and doing; always place moral education in a prominent place; pay attention to all-round development. After the analysis, we can safely draw the conclusion that many of Confucious' educational theories are applicable in English class and we should make good use of them to achieve better results in English teaching and learning.
\end{abstract}

Keywords-Confucius; educational thought; enlightenment; learning and thinking; knowing and doing

\section{INTRODUCTION}

Confucius is known as "the teacher of all ages". Today, Confucius is widely respected throughout the West. The Americans regard Confucius as the world's top ten thinkers; the Germans treat Confucius and Kant as the founders of education. Confucius' educational thought has a profound impact on later generations. The Analects was compiled by Confucius' disciples and was believed to be the recordings of Confucious' words or opinions. It is the main material for studying the educational thought of Confucius.

\section{The Current SITUATION of Education Chaos}

In the field of college education or education as a whole, we seem to be lost in so many theories and become accustomed to this condition, such as Constructivism, Learning Community and Returning to Life. Education experts, administrative officials and teachers each air out their own educational ideas and act in their own ways. What's worse, they say one thing and do another. In a nutshell, we have entered an era of "education chaos". This shows the poverty of educational principle in the macro level, and the confusion in the micro level. The chaos in education is not necessarily a bad thing. At least it can cultivate the soil for all kinds of educational practice and activate the thought of educators. Nowadays, the various ratings of famous teachers at all levels are everywhere, and the training of college English teachers is countless. It should have worked, but it produces little results. Now we seldom have such educators like Cai Yuanpei, Huang Yanpei, Liang Shuming, etc., not to mention the great educator Confucius who has extensive and far-reaching influence on the world.

In the English teaching field of colleges or universities, many teachers and researches are constantly studying the characteristics and laws of English language, culture and English teaching. To be sure, many English teachers are also studying Chinese traditional culture and Western culture for comparison and contrast in order to better serve their teaching practice. However, there are few English teaching staff who are really interested in Confucius' educational thought. Since there is no in-depth study, it is difficult for them to grasp the essence of Confucius' educational thought, and thus combine it with English teaching practice.

\section{CONNOTATIONS OF CONFUCIUS' EDUCATIONAL THOUGHT AND ITS IMPLICATIONS FOR ENGLISH TEACHING}

Confucius' educational thought is a systematic educational theory itself and has close relationships with the reform and development of contemporary education, such as his thought on "teach students in accordance with their aptitude", enlightenment, "combination of learning and thinking", "unity of knowing and doing" and creative education. Thus it can serve as a significant guidance for today's educational practice, and also for English teaching and education. We should make good use of Confucious' theories of education principles, education subjects, education objects and teaching methods to provide reference and guidance and better serve the college English teaching practice.

\section{MAKing Use of CONFUCIOUS' EDUCATIONAL THOUGHT TO BETTER SERVE COLLEGE ENGLISH TEACHING}

\section{A. Reform of English teaching and change of teachers' role}

For a long time, the traditional educational model treats students as the learning objects instead of subjects, and all activities are subjectively carried out by the teacher. Students are thus placed in a subordinate position, which is a most typical phenomenon in Chinese classrooms. Teachers spare no efforts to inculcate, with the students fiercely taking notes. Thus in the classroom setting, students seldom have 
opportunities to participate actively. As teachers, we should change from the "knowledge inculcator" into "the designer of situation teaching". Before the class, the teacher should decide on the contents to be taught and be clear about the important and difficult teaching points, and he must know well about the objects and choose appropriate teaching methods in accordance with the teaching contents and objects and design various teaching activities. Confucius once said, "We can talk about profound truth with someone above mean aptitude, but not with someone below it." By this we don't mean that Confucious is snobbish and discriminate against those with low aptitude, but that Confucius can face the differences in students' aptitude, interests, intelligence and abilities. According to The Analects, Ran Qiu (one disciple of Confucious) was timid and overcautious. Confucius taught him to be decisive; Zhong You (another disciple) was bold, yet rash and thoughtless. Confucius taught him to think twice before doing everything in case he got into trouble. From this we can see that Confucius made good use of their advantages and bypassed their disadvantages. Teachers should design tasks of different levels based on students' characters and knowledge mastery, so that neither will the students with poor English experience a sense of frustration, nor will those with a high level lose interest in completing too simple a task so that everyone may learn something and benefit from these activities. We can compare student to an actor, and a teacher to a director. The principal duty of a teacher is to manage and guide the teaching activities. We should use the teaching syllabus to guide us the right direction in the macro level, and design and manage each classroom activity accordingly. From the practical point of view, not only can people create cultural knowledge and material wealth, but also they can transform a variety of civilizations into inner spirits. The development of human culture undeniably profits from those internalized and externalized activities. To make the cultural products internalized by individual is just what the essence of education is about. The fundamental aim of education is not to copy knowledge and skills, but to turn those knowledge and skills into subjective abilities of the educated. Therefore, every person's learning of any knowledge is the process of individual subjectivity of cultural achievements, and such individual subjectivity is the education process itself.

\section{B. Combination of learning and thinking and unity of knowing and doing}

Confucius said: "Those who know how to learn are not as good as those who like learning, and those who like learning are not as good as those who enjoy learning." "Learning without thinking is lost, thought without learning is perilous." "Learning" means to possess and know about knowledge materials, and "thinking" is the analysis and reflection of the knowledge materials. For a man to become useful, he must get to know about those knowledge materials and can also think independently.

As English teachers, we should learn to be good at enlightening step by step. English course is not like other courses, and it is featured by its communication function and tool orientation. We should not just emphasize the knowledge facts of words, phrases or grammar points. Instead, we should inspire the students to think for themselves and practice in order to master the usage of language facts, or to extend our understanding to a wider range of similar words or sentences because the English language is boundless and always offers something new for us to learn. We should always memorize the two points in English learning, to think more and to practice more. Brown [1] puts forward several principles of Communicative Approach, who says English teaching should have the following four characteristics: 1) The center of classroom activities should be all communicative, and should not be confined to grammar or language facts; 2) The designs of language learning methods should aim to help students master the actual use of language in a meaningful way in practical, real situations; 3) Treat fluency and accuracy as two complementary principles of communication strategies; 4) In communicative classrooms, the ultimate goal of learning must be the comprehending use of language in unrehearsed scenes, and language should be productive. Of the four points advocating "doing", we can feel the importance of "thinking" (or reflection) in English teaching process between the lines.

Confucius said, "We shouldn't enlighten someone until he has had quite some serious thought but still can't figure out, nor give him a clue until he has understood it but still can't express it. If you teach someone one fact but he couldn't infer other things from it, stop teaching him more." That's to say, we should give students time to ponder, and only enlighten him after he has contemplated for quite some time but still can't figure out, or when he has understood it but can't express it in proper words. The teacher's inspiration is based on students' thinking and students should be encouraged to think again after they have been inspired so as to gain further understanding.

Confucius proceeded with this enlightening methods in an orderly way step by step and three methods were mainly employed by him. That is: Proceed from shallow to deep, from easy to difficult; place oneself in another's place---to do unto others what one would do unto oneself; don't go to extremes.

Confucius advocated the combination of learning and thinking and unity of knowing and doing and believed the actual implementation of teaching contents should be divided into four stages, namely learning, thinking, reviewing and doing. This idea was later inherited and developed, and in the name of Confucious, it was summed up as "we should learn extensively, inquire about it intensively and in detail, think cautiously, distinguish between right and wrong and sincerely carry it out."(From The Doctrine of the Mean)

The theory of teaching process stages has a profound and positive impact on the reform of English teaching in China. In the past, the English teaching attached great importance to language structure, ignoring the communicative function of language itself. Now our notion is changed and much more attention is paid to the communication-oriented new curriculum. Xu Qiang [2] puts forward three principles of communicative approach: 1) All the activities should center on communication; 2) Try to reproduce the communication process; 3) Do not always correct the errors. The main difference between the traditional English teaching methods and the Communicative Approach lies in their attitudes towards the cultivation of language ability and communicative 
ability. The traditional teaching methods emphasize the form of language, and the Communicative Approach pays more attention to the meaning of language in actual use, and emphasizes the appropriateness of language use, namely, pragmatics. For English teaching, it is essential to cultivate the ability of communication (doing), for the final objective of English learning should be embodied in the comprehensive application of "listening, speaking, reading and writing". To embody the communicative function of language, the teaching process must be the "combination of learning and thinking" and "unity of knowing and doing".

The three stages of "learning", "thinking" and "reviewing" are the process of students' knowledge acquisition under the guidance of teachers, and "doing" appears when students have mastered certain knowledge structures and could turn knowledge into actual use. The cultivation of communicative competence should be based on the development of language ability [3]. We consolidate "learning" through "doing" and testify "thinking" by "doing". In so doing we get to a higher level of "learning" and "thinking", which in turn are applied to the teaching phase of "reviewing" and "doing", thus achieving the goal of college English teaching and realize the communicative function of language.

\section{Always place moral education in a prominent place}

Moral cultivation is the most basic content of Confucius' education. The most important element is "benevolence". Confucious believes that "we should bear filial piety towards our parents at home and be friendly to our brothers and respect the elder people outside; be cautious in our words and deeds; keep the promises we have made; be fraternal to others and close to the benevolent people." Obviously, Confucius put moral education in the first place, that is, "learn to be" comes before "learn to do". College English Course Teaching Requirements (A document by Higher Education Department of the Ministry of Education 2007, No. 3) coincide with Confucious' education thought in terms of moral education. When we strive to achieve the knowledge and ability goal, we should also note the quality goal. While inspiring students to pursue knowledge, we should also teach them how to be a good person and establish the right attitude towards life. While teaching them the foreign language and culture and cultivate the cross-cultural awareness and ability, we should also inculcate the elements of patriotism and tell them to love our traditional culture [4].

\section{Pay attention to all-round development}

Confucius advocated the training of "six arts" in order to achieve the all-round development of students, namely rite, music, archery, driving a chariot, learning and mathematics, among which rite is used to maintain "human relations and moral norms, for as the saying goes, there is no better way to govern the people than "rite"; "music" is the art of music, dance, poetry, etc. that is used to exert a gradual moral influence on the students and is believed to be the best way to change customs and traditions. We thus can see "rite" and "music" work together to implement the moral education. "Archery" means the military combat skills with shooting as the main means, together with "driving a chariot" constitute the military sports education. "Learning" consists of literacy and reading. "Mathematics" has something to do with modern mathematics but is much simpler and also includes calendar knowledge. So these two aspects are similar to the two subjects Chinese and mathematics nowadays and about cultural and scientific knowledge education. From the above mentioned, we can see Confucius has at least included the four teaching contents of moral education, art education, scientific and cultural education, and physical education (mainly skills training). We know from the previous section that Confucious always placed moral education [5], the education of teaching people to be benevolent people, in the first and foremost place. Confucious' educational thought of all-round development is also applicable in the college English teaching process. Besides the moral education, we should also increase the discussion or appreciation of literary works both in and out of the class, exerting a gradual influence on the students' aesthetic standards, which is similar to the art education; as every English major has his or her own learning direction, for example, normal direction, translation direction, business English direction etc., we should strengthen their skill training to make them fully qualified for the future work. Besides the common language and grammar points, those normal students need to know more about how to be a good teacher, which may involve such subjects as pedagogy and educational psychology, etc.; the translation students should know something about translation theories and skills; the business English students should know as much as possible about business, which is almost a brand new branch!

\section{CONCLUSION}

Since Confucious' educational thought has guided the right direction for us to follow, we, as college English teachers, should strengthen our own cultivation, change those outdated concepts of traditional teaching methods and teachers' role in class, learn to be good at enlightening students and cultivate students' unity of knowing and doing, and always place moral education in a prominent position. Try our best to foster students that are diligent with truth-seeking and enterprising spirit and create a friendly interactive atmosphere between students and the teacher, which in turn leads to the improvement of both teaching and learning.

\section{REFERENCES}

[1] Brown,H. D. Principles of Language Learning and Teaching [M]. Shanghai: Shanghai Foreign Language Education Press, 2001.

[2] Xu, Qiang. Communicative English Teaching and Testing Assessment [M]. Shanghai: Shanghai Foreign Language Education Press. 2000.

[3] Yuan, Changhuan. Middle School Englsih Teaching Theories and Practice in the 21 Century [M]. Beijing: Beijing Broadcasting University Press, 2002.

[4] China Qufu Wedsite. The Most Holy Confucious_Confucious' EducationThought [EB/OL]. http://www.qufu.gov.cn/show.aspid=41,2012-5-1.

[5] Kang, Youwei. Notes to the Analects[M]. Beijing: Zhong Hua Book Company, 1984. 